\title{
Synthesis of iron chelates for remediation of iron deficiency in an alkaline and calcareous soil
}

\author{
Murali Subramani* \\ Department of Soil Science and Agricultural Chemistry, Tamil Nadu Agricultural University, \\ Coimbatore - 641003 (Tamil Nadu), India \\ Jawahar Durairaj \\ Department of Soil Science and Agricultural Chemistry, Tamil Nadu Agricultural University, \\ Coimbatore - 641003 (Tamil Nadu), India \\ Chitdeshwari Thiyagarajan \\ Department of Soil Science and Agricultural Chemistry, Tamil Nadu Agricultural University, \\ Coimbatore - 641003 (Tamil Nadu), India \\ Jagadesh Muthumani \\ Department of Soil Science and Agricultural Chemistry, Tamil Nadu Agricultural University, \\ Coimbatore - 641003 (Tamil Nadu), India \\ *Corresponding author. Email: muralijai333@gmail.com
}

\section{How to Cite}

Subramani, M. et al. (2021). Synthesis of iron chelates for remediation of iron deficiency in an alkaline and calcareous soil. Journal of Applied and Natural Science, 13 (SI), 149 - 155. https://doi.org/10.31018/jans.v13iSI.2818

\begin{abstract}
The present study was aimed to investigate the using iron chelates viz., ferrous glycinate and ferrous citrate for the remediation of iron deficiency in alkaline and calcareous soil. The lab experiment was carried out to study the synthesis of Fe chelates by using organic and amino acid based chelating agents. The Fe chelates were synthesized based on 2:1 molar ratio of chelating agents and metal ions. The synthesized iron chelate was characterized by using Fourier transform infrared spectrophotometer (FT-IR). Finally, the synthesized amino acid and organic acid chelated iron were used to remediate the calcareous soil with black gram as a test crop. Iron content in black gram (above ground mass) tented to fluctuate at different growth stages. The highest shoot iron content of 325,351 and $347 \mathrm{mg} \mathrm{kg}^{-1}$ at vegetative, flowering and harvest stages were recorded with $1 \%$ ferrous glycinate as foliar spraying on 25 and 45 Day after sowing (DAS). The root iron content was also higher in $1 \%$ ferrous glycinate as foliar spraying on 25 and 45 DAS. The current investigation affirmed that the utilizing different chelating agents like the ferrous glycinate were powerful than ferrous sulfate, which may build the iron substance and iron take-up of blackgram in various development stages.
\end{abstract}

Keywords: Black gram, Calcareous soil, Ferrous glycinate, Iron uptake

\section{INTRODUCTION}

Iron deficiency is a typical issue for some plants developed in alkaline and calcareous soils, causing the indication known as iron chlorosis. Fe deficiency (FD) often occurs in alkaline soils. Fe becomes insoluble and immobile, leading to lesser root uptake from soil due to high soil $\mathrm{pH}$; an excessive amount of calcium carbonate, nitrate, and heavy metals; poor aeration; unbalanced cation ratios; and temperature changes (Kobayashi et al., 2014). The use of iron chelates solves the problem of iron deficiency in alkaline and calcareous soils. Iron is a catalyst in the production of chlorophyll and is involved in several plant enzyme systems. The uptake form of iron is $\mathrm{Fe}^{++}$cation. Iron deficiency symptoms show interveinal chlorosis, i.e. yellow to white leaf color in which veins remain green. The appearance of deficiency symptom on younger leaves develops, which remain nearer to the plant top (Schulte and Kelling, 2004).

Natural amino acids are very small molecules that chelate with micronutrients are quickly absorbed, translocated and metabolized by plants. The merits of amino acid chelates are that the amino acid ligand frame and defend the micronutrients from adverse relations usually take place in soil solution, in the presence of soil or 
on leaf surfaces (Schaffer et al., 2011). Various examinations have demonstrated that the likely limit of iron compounds to address iron lacks in plants developed in alkaline and calcareous soils relies upon two fundamental features (Chaney and Bell, 1987) viz. (i) the limit of iron compounds to keep up solvent iron in soil arrangement and (ii) the limit of plant roots to absorb the iron from the iron compounds present in soil solution.

Definitely the two components are validly identified with the solvency and steadiness of the iron compounds in soil solution. When the plant ability to acclimatize iron from the iron compound has been shown under hydroponic conditions, a potential method to assess the possible viability of the iron compound under soil conditions is study the variety in grouping of the total iron and the iron compound in soil solution after some time (Josemaría et al., 2003). In spite of the fact that foliar application is by all accounts compelling in taking care of issues of micronutrients, notwithstanding, leaf fertilizer with an inorganic mineral structure scarcely diffuses from leaf surface into the plant due to high weight molecular structure (El-Seginy et al., 2003).

Amino acids are tolerably hard chelating agents. When they enter inside the plant, the mineral is discharged and the plant utilizes leftover amino acids that shaped the defensive shell as a wellspring of water-solvent nitrogen. Amino acids are building blocks in cell apparatus. Everything is utilized and nothing is lost. Then again, EDTA is a synthetic particle, and plants do not normally utilize EDTA. Amino acid chelates are commonly fundamental in the plant, meaning they move and travel to where they are required. They can do this since the plant perceives amino acids as building squares and are utilized in almost every tissue in the plant. Amino acid chelates are accessible as fluids or powders and, by and large accessible for use in natural food creation. Glycine chelates (otherwise called glycinates) are a subset of amino acid chelates. It is the minutest amino acid and it is frequently utilized as a chelating agent. Since glycine is little, it makes a little last item that goes through leaf stomata more effectively than other bigger molecules, in this way upgrading plant take-up. At the point when glycine is isolated from the mineral in the plant, the plant utilizes glycine. As amino acid chelates effectively enter the plant, they are amazingly valuable for rectifying supplement inadequacies rapidly. The amino acid chelates do not cause a burning impact in plants; then again, EDTA - metal chelates are phytotoxic or show consumption of plant tissues when appropriate consideration is not taken (Datir et al., 2010).

Foliar application is credited with the advantage of quick and efficient utilization of nutrients, elimination of losses through leaching and fixation, besides helping in regulating the uptake of nutrient by plants (Manonmani and Srimathi, 2009). Foliar application of nutrients using water-soluble fertilizer is one of the possible ways to enhance the productivity of pulses like green gram and black gram. Hence the present study was proposed to develop iron chelates to increase the iron use efficiency and to evaluate its effect on crop yield in calcareous soil.

\section{MATERIALS AND METHODS}

\section{Laboratory experiment}

The laboratory experiment was carried out to study the synthesis of $\mathrm{Fe}$ chelates by using organic and amino acid based chelating agents. The synthesized iron chelate was characterized.

\section{Synthesis of iron chelates}

1,000 grams of water was boiled for 30 minutes to remove dissolved air. 170 grams of ferrous sulfate monohydrate was dissolved in $500 \mathrm{ml}$ of the deaerated water and the solution was maintained at $80^{\circ} \mathrm{C}$ and 30 grams of citric acid was mixed to it (Fig. 1). Separately 150 grams of glycine was dissolved in $500 \mathrm{~m}$ of deaerated water and the acid solution was added to the ferrous sulfate solution with stirring. The temperature of the mixture was maintained at about $80^{\circ} \mathrm{C}$. The mixture was filtered to remove any undissolved materials. The metal amino acid citrate was dried at about less than about $110^{\circ} \mathrm{C}$ and the dry material was ground to a fine powder. (Hsu, 1995)

\section{Chelate analysis}

The analysis was carried out in Fourier transform infrared spectrophotometer (FT-IR) 6800 (Jasco, Japan) equipped with ATR PRO ONE accessory and TGS detector. Registration was carried out in the region $400-$ $4000 \mathrm{~cm}^{-1}$ (resolution $4 \mathrm{~cm}^{-1}$ with a number of scanes 40). The report was then processed using origin ${ }^{\circledR} 8.0$ software and interpreted.

\section{Schrodinger maestro suite}

The software used for the research work is Schrodinger maestro suite v. 2015-16. It is a collection of tools and interfaces that are designed to assist calculations which are significant to biological molecules. The maestro interface organizes access to the interactive tools for use in biological projects. Maestro helps in the basic structure manipulation, demonstration and organization characteristics of the interface and is an integrated interface for all the Schrodinger software.

\section{Characterization of structure}

The molecular models of ferrous glycinate and ferrous citrate were generated initially using ACD chemsketch. The 3D optimization was performed and the 3D atomic coordinates were collected. The modules were further 
visualized and analysed using Schrodinger's maestro interface.

\section{Pot culture experiment}

The pot culture experiment was conducted on black gram (Vigna mungo. L) at Tamil Nadu Agricultural University, Coimbatore to find out the effect of amino acid and organic acid chelated iron on growth and productivity of black gram in iron-deficient calcareous soil with nine treatments involving $\mathrm{T}_{1}-\mathrm{NPK}$ control, $\mathrm{T}_{2}-\mathrm{FeSO}_{4}$ $25 \mathrm{~kg} \mathrm{ha}^{-1}$ as a basal soil application, $\mathrm{T}_{3}$ - Ferrous glycinate chelate @ $5 \mathrm{~kg} \mathrm{ha}^{-1}, \mathrm{~T}_{4}$ - Ferrous citrate chelate @ $5 \mathrm{~kg} \mathrm{ha}^{-1}, \mathrm{~T}_{5}$ - Fe - EDTA chelate @ $5 \mathrm{~kg} \mathrm{ha}^{-1}$, $\mathrm{T} 6-1 \% \mathrm{FeSO}_{4}$ as foliar spraying on $25 \& 45 \mathrm{DAS}, \mathrm{T}_{7}$ $1 \%$ Ferrous glycinate as foliar spray on 25 \& 45 DAS, $\mathrm{T}_{8}-1 \%$ Ferrous citrate as foliar spraying on 25 and 45 DAS, and T9 - 1\% Fe - EDTA as foliar spray on 25 and 45 DAS was planned in potted plants with three replicates. The plant analysis of iron content was carried out with the help of atomic absorption spectrophotometer.

\section{Statistical analysis}

The data obtained from the experiments was analysed statistically to find out the effects of various treatments and their interactions. Data recorded from three replications were subjected to single way analysis of variance (ANOVA), and critical differences were calculated at $p=$ 0.05 level.

\section{RESULTS AND DISCUSSION}

FTIR spectrum characteristics of ferrous glycinate FTIR analysis shows unbound glycine from chelated one (Fig. 2). Free glycine exhibited a vibration peak at $2920 \mathrm{~cm}^{-1}$ that disappeared upon chelate formation. The peak at $2920 \mathrm{~cm}^{-1}$ was due to the twisting and vibration of $\mathrm{NH}_{2}$ groups. The disappearance of this peak indicates that a new coordinate bond was formed through the terminal amine groups. The peak at $3153.04 \mathrm{~cm}^{-1}$ and $1327.75 \mathrm{~cm}^{-1}$ was due to the weak stretching of symmetric and asymmetric amine vibration. As compared to the position of bands in the spectrum of iron glycinate, it confirms the chelation of amino acid with $\mathrm{Fe}^{2+}$ ions. Similar results were reported by Ahamed et al. (2019) in infrared spectroscopy of pure glycine revealed several peaks which ranged from $2500 \mathrm{~cm}^{-1}$ to $3200 \mathrm{~cm}^{-1}$ where $2520.51 \mathrm{~cm}^{-1}, 2603.43$ $\mathrm{cm}^{-1}, 2703.71 \mathrm{~cm}^{-1}, 3001.66 \mathrm{~cm}^{-1}$ and $3149.17 \mathrm{~cm}^{-1}$ (OH groups) observed sharp peaks. A peak at 1056.8 $\mathrm{cm}^{-1}$ characteristics of sulphate was observed in zinc sulphate heptahydrate. The FT-IR spectral investigations of synthesized chelate indicated peaks at 1065.48 $\mathrm{cm}^{-1}\left(\mathrm{SO}_{4}{ }^{2-}\right), 1393.33 \mathrm{~cm}^{-1}$ (COO--) and $3169.44 \mathrm{~cm}^{-1}$ $(\mathrm{OH})$. Broadband from $2700 \mathrm{~cm}^{-1}$ to $3300 \mathrm{~cm}^{-1}$ with a centroid at $3169.44 \mathrm{~cm}^{-1}\left(\mathrm{NH}_{2}\right.$ broad peak) was also observed.

\section{FTIR Spectrum characteristics of ferrous citrate}

FTIR spectrum of citric acid at wavelength $3317.93 \mathrm{~cm}^{-1}$, $3219.88 \mathrm{~cm}^{-1}$ and $3014.19 \mathrm{~cm}^{-1}$ was due to broad stretching of carboxyl groups $\left(\mathrm{COO}^{-}\right)$. The peaks at $2668.03 \mathrm{~cm}-1,2551.36 \mathrm{~cm}^{-1}$ and $1950.64 \mathrm{~cm}^{-1}$ was assigned to weak stretching of $\mathrm{OH}$ groups and aromatic over ton vibrations. The peak in FTIR at 1718.26 $\mathrm{cm}^{-1}$ and $1205.20 \mathrm{~cm}^{-1}$ was assigned to the very sharp stretching of $\mathrm{C}=\mathrm{O}$ group and $\mathrm{C}-\mathrm{O}$ group (Fig. 3). Spectrum of $\mathrm{Fe}^{2+}$ - citrate was compared with citric acid, shown that the spectrum of $\mathrm{Fe}^{2+}$ citrate contains only one weak broadband of high intensity in the range from $3000 \mathrm{~cm}^{-1}$ to $3500 \mathrm{~cm}^{-1}$ with centroid at $3281.29 \mathrm{~cm}^{-1}$, which could have been attributed to valance vibrations of $\mathrm{OH}$ stretching. The wavelength of $1742.37 \mathrm{~cm}^{-1}$ and $1695.12 \mathrm{~cm}^{-1}$ was assigned to sharp and strong $\mathrm{C}=\mathrm{O}$ bending vibrations. As compared to positions of these bonds in the spectrum of citric acid, it confirms the presence of $\mathrm{C}=\mathrm{O}$ groups in the structure of $\mathrm{Fe}^{2+}$ - citrate. Two bonds originate from valence vibrations of carboxyl anion ( $\left.\mathrm{COO}^{-}\right)$, which interacts with iron ion. Compared to positions in the spectrum of $\mathrm{Fe} 2+$ - citrate, these bonds are exhibited in the citric acid spectra, indicating coordination of carboxyl group and $\mathrm{Fe}^{2+}$ ion. Similar results were reported by Ahamed et al. (2019), zinc sulphate heptahydrate, the peak corresponding to the sulphate bond at $1056.8 \quad \mathrm{~cm}^{-1}$ was obtained. However, in the new chelate viz, of zinc citrate sulphate, FT-IR analysis pointed out sharp peaks at $1641.13 \mathrm{~cm}^{-1}, 3742.19 \mathrm{~cm}^{-1}, 3828.97 \mathrm{~cm}^{-1}$ and $3844.4 \mathrm{~cm}^{-1}$. A weak broadband with a width of 2700 $\mathrm{cm}^{-1}$ to $3400 \mathrm{~cm}^{-1}$ with a centroid at $3281.29 \mathrm{~cm}^{-1}(\mathrm{OH}$ group) was noticed.

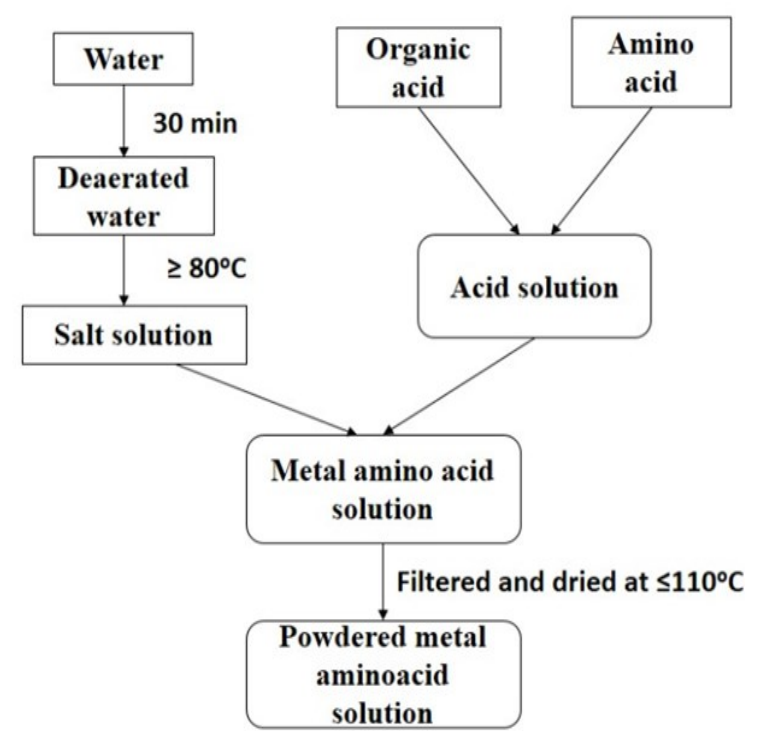

Fig. 1. Synthesis of iron chelate. 


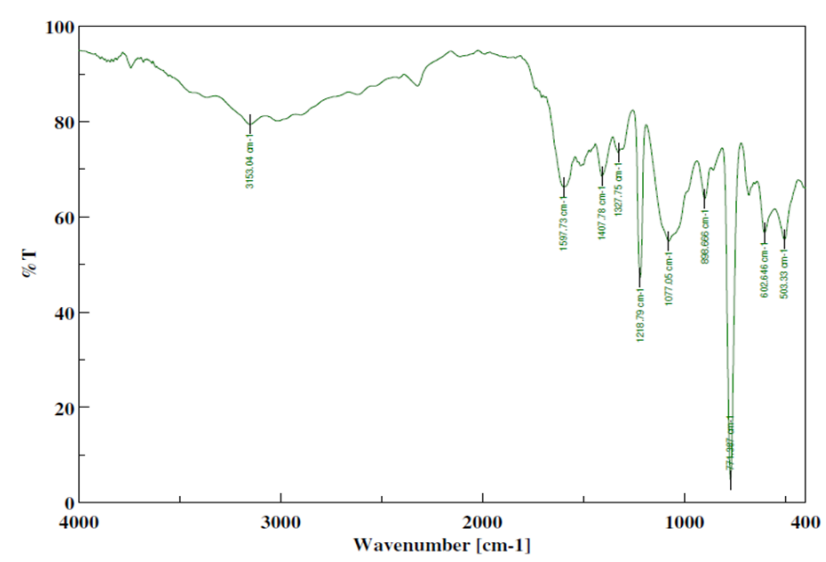

Fig. 2. FTIR Spectrum of ferrous glycinate.

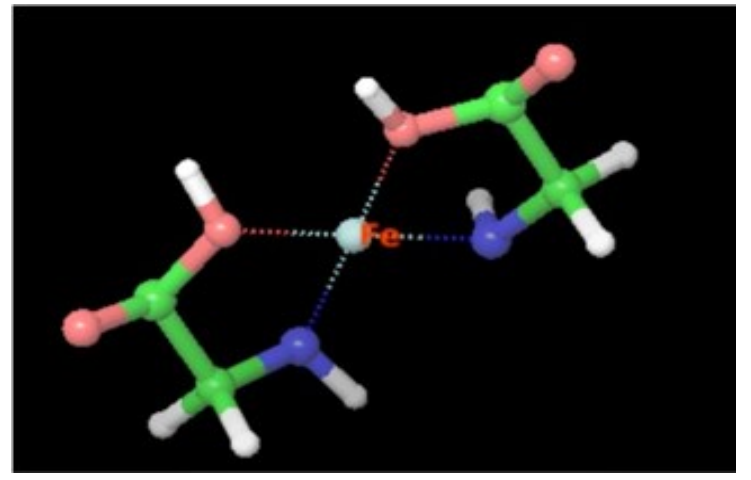

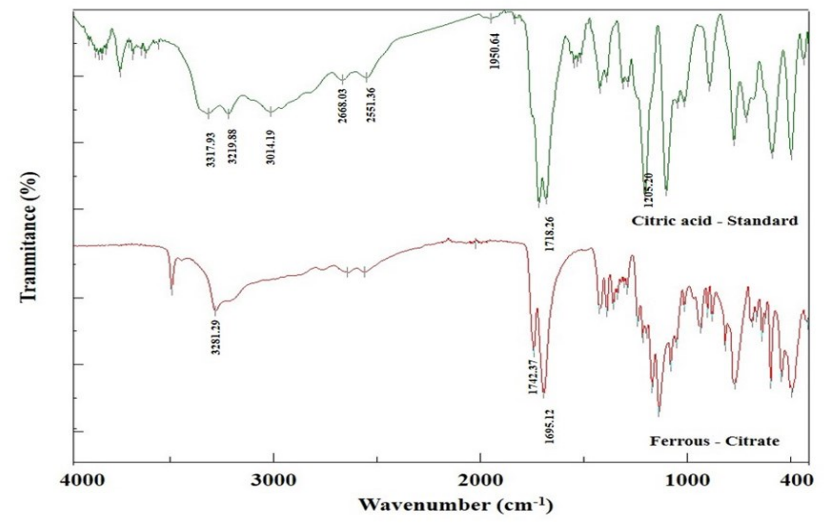

Fig. 3. FTIR spectrum of $\mathrm{Fe}$ - Citrate.

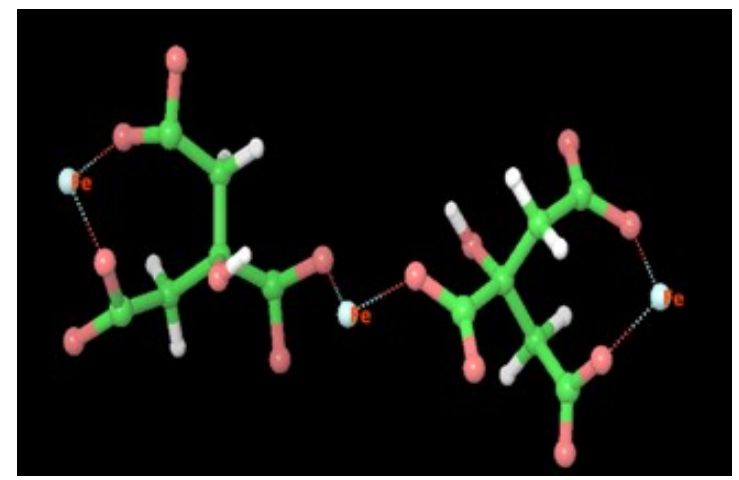

Fig. 4 \& 5. Structure of ferrous glycinate and ferrous citrate.

\section{Characterization of iron chelates}

The coordination geometry of chelated ferrous glycinate and ferrous citrate have been presented in Fig. 4 and Fig. 5. The predicted energy valve of the chelated molecule in $38.47 \mathrm{k}$. cal mol ${ }^{-1}$ indicated that the molecule was relatively stable. The ferrous glycinate structure, the carboxyl group and $\alpha$ - amino group of glycine both donate electron pairs into the ferrous iron cation forming a coordinate covalent bond. Dry matter production of root and shoot

An increase in DMP with the advancement of crop growth and the increase between flowering and maturity were also marked. The increase in DMP at flowering might be mainly related to the increase in branches, number and size of leaves and higher photosynthesis due to an increase in leaf area. The highest DMP at vegetative, flowering and harvest stages recovered by treatment $T_{7}$, namely foliar spraying of $1 \%$ ferrous glycinate at 25 and 45 DAS (Table 1) which is on par with soil application ferrous glycinate $\left(\mathrm{T}_{3}\right)$ at $5 \mathrm{~kg} \mathrm{ha}^{-1}$. Kumar et al. (2015), also observed that sources and mode of iron application also had a significant effect on dry matter production. The lowest dry matter accumulation was recorded with the control plot, which was significantly lower than 2 and 3 foliar sprays of $2.0 \%$ iron sulphate and $0.5 \%$ iron chelate at all the stages. The better performance of foliar spraying of $1 \%$ ferrous glycinate $\left(T_{7}\right)$ at 25 and 45 DAS treatment on DMP in the present study could be due to the fact that the plants absorb and transport iron efficiently in its glycinate form, i.e., glycine helps maintain the iron in its soluble form within the plants. In the present study, the treatment $\mathrm{T}_{7}$ viz., foliar spraying of Fe chelate at 25 and 45 DAS (15.2\% present in iron) which might be attributed to the $15.2 \%$ of iron supply by the ferrous glycinate. Further, the iron availability and translocation to crop in iron-deficient soil under the treatment $T_{7}$ could be the reason for enhanced DMP observed in the present study.

Soil application of $\mathrm{FeSO}_{4}$ at $25 \mathrm{~kg} \mathrm{ha}^{-1}$ as inorganic salt did not perform well in increasing the DMP in comparison with $\mathrm{T}_{7}$. According to Pal et al. (2008), the effectiveness of Fe supplements through inorganic source may be attributed to its quick conversion from $\mathrm{Fe}^{2+}$ to $\mathrm{Fe}^{3+}$ under field condition, which is a highly stable and insoluble form. These findings corroborate our results since experimental soils were calcareous in nature.

\section{Iron content (Shoot and root)}

The increase in plant growth was mainly due to a gradual increase in iron content in the shoot. (Table 2). Iron content in black gram (above ground mass) tented to fluctuate at different growth stages. The highest shoot iron content of 325,351 and $347 \mathrm{mg} \mathrm{kg}^{-1}$ at vegetative, flowering and harvest stages respectively were recorded with $1 \%$ ferrous glycinate as foliar spraying on 25 and 45 DAS, which were on par with foliar spraying of 


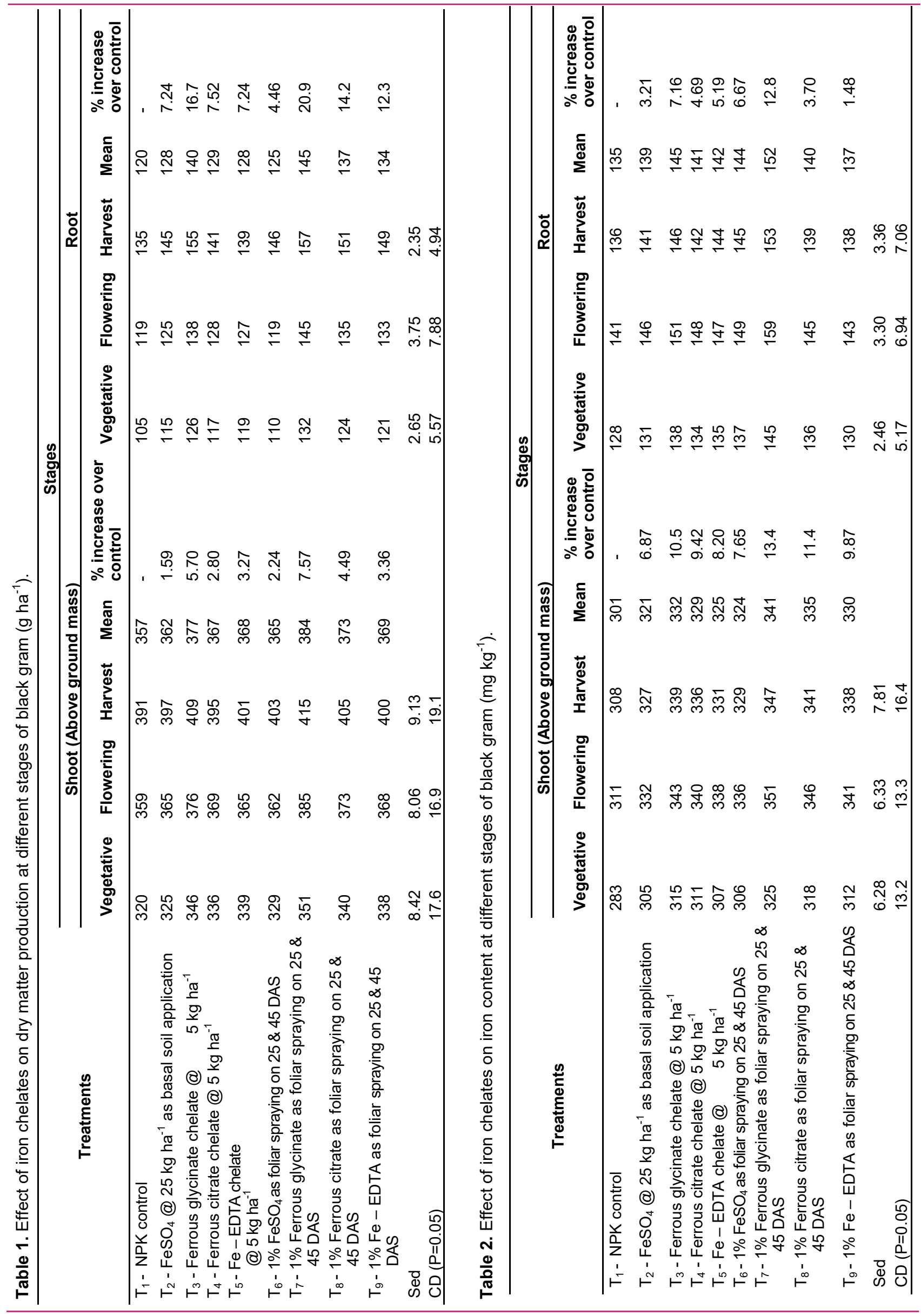




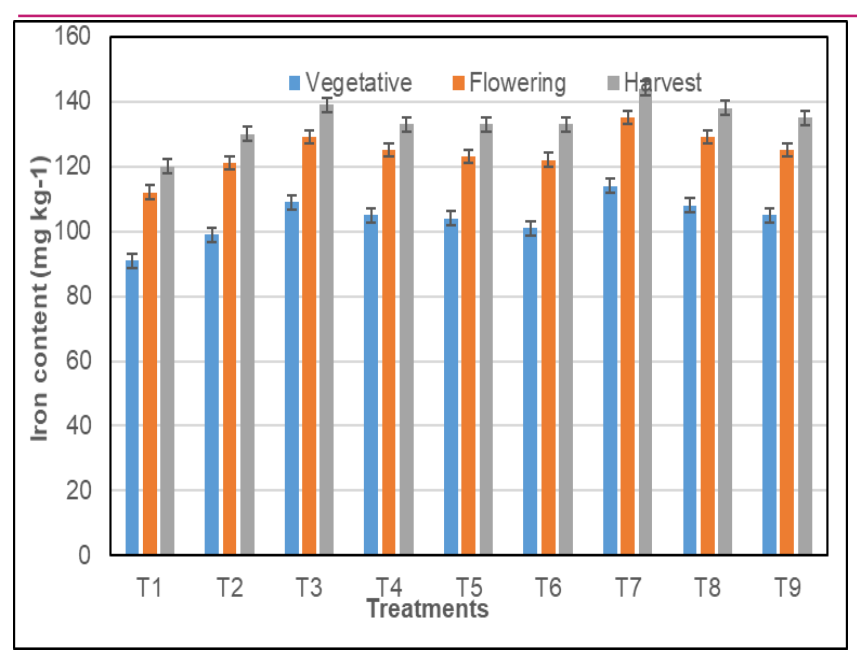

Fig. 6. Effect of iron chelates on iron content at different stages of black gram $\left(\mathrm{mg} \mathrm{kg}^{-1}\right)$.

$1 \%$ ferrous citrate $\left(T_{8}\right)$ of 318,346 and $341 \mathrm{mg} \mathrm{kg}^{-1}$ at vegetative, flowering and harvest stages respectively (Fig. 6). Foliar application of ferrous glycinate in black gram expressed a higher amount of $\mathrm{Fe}$ in their shoots than other treatments. Our study indicated that using ferrous glycinate chelate in the foliar application could supply sufficient Fe for plant uptake and improve the shoot and root growth of black gram. Mohammadipour et al. (2013) also observed that highest of plant $\mathrm{Fe}$ value (454.5 ppm) was obtained from the $\mathrm{FeSO}_{4}$ and Fe-EDTA with 91.17 ppm caused to the lowest Fe value. $\mathrm{Fe}$ value in $\mathrm{FeSO}_{4}$, EDDHA, iron nano fertilizer treatments was more than the optimum range $(50-300$ ppm) for Spathiphyllum plant.

Amino acids induce biosynthesis of chlorophyll and thereby improve the photosynthesis rate (Amin et al., 2011; Zeid 2009). The highest root Fe content of 145, 159 and $153 \mathrm{mg} \mathrm{kg}^{-1}$ at vegetative, flowering and harvest stages respectively was recorded in the treatments that received $1 \%$ ferrous glycinate as foliar spraying on 25 and 45 DAS which followed by soil ap-

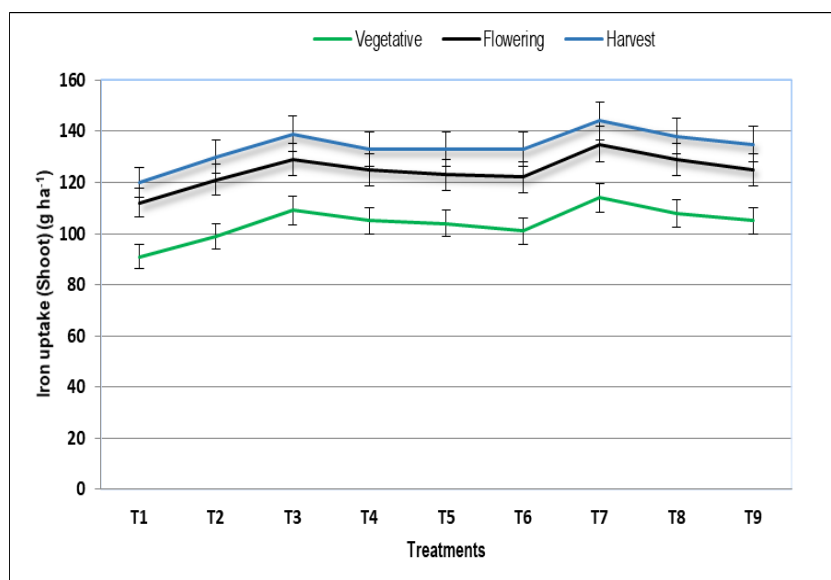

a.) Shoot plication of ferrous glycinate at $5 \mathrm{~kg} \mathrm{ha}^{-1}\left(\mathrm{~T}_{3}\right)$ of 138,151 and $146 \mathrm{mg} \mathrm{ha}^{-1}$. Although amino acids used in the present study stimulated plant growth, it is not easy to dissect whether the effect is due to better Fe uptake, more nitrogen supplied in the form of amino acids, or the hormonal effect of amino acids (Ghasemi et al., 2012).

\section{Iron uptake (Shoot and root)}

The results showed an increase in the iron uptake by shoot and root at different stages and maximum $\mathrm{Fe}$ uptake was recorded at harvesting stages (Fig.7). The different treatments significantly influenced the Fe uptake at different stages and a similar trend was noticed in the case of DMP. Increased DMP coupled with higher iron concentration resulted in higher uptake of $\mathrm{Fe}$ in the present investigation. Foliar spraying of $1 \%$ ferrous glycinate @ 25 \& 45 DAS recorded the maximum iron uptake by both shoot and root at all the growth stages. Zimbovskaya et al. (2020) also reported that $70-75 \%$ higher iron content in washed and dried wheat shoots compared to a coordination complex of ferric ions and ethylene diamine tetraacetic acid (Fe-EDTA). The higher uptake of iron from the ferrihydrite $(\mathrm{FeH})$ stabilized with HS was related to the enhanced wettability of the wheat leaves.

\section{Conclusion}

Among the organic and amino acids, iron chelates tested in the present investigation, the foliar spraying of iron chelates was superior in increasing the iron content and iron take-up of black gram under pot situations because of its mainly higher iron uptake. Amino acids prompt the biosynthesis of chlorophyll and. in this manner, improve the photosynthesis rate. Although amino acids used in the present study stimulated plant growth, it was not easy to dissect whether the effect was due to better Fe uptake, more nitrogen supplied in the form of

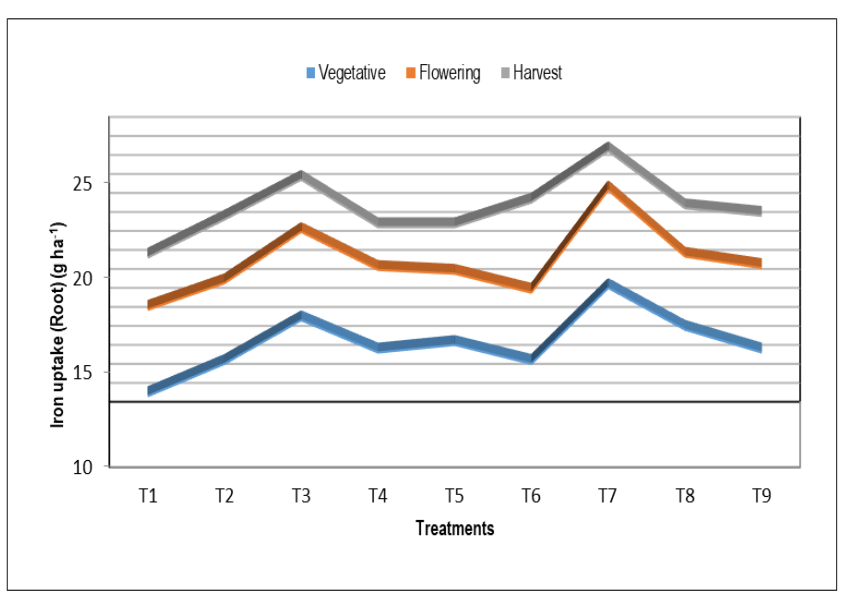

b.) Root

Fig. 7. Effect of iron chelates on iron uptake at different stages of blackgram ( $g$ ha-1). 
amino acids or the hormonal effect of amino acids. So, amino acid chelated iron was more effectively explaining the iron inadequacy in calcareous and alkaline soil.

\section{ACKNOWLEDGEMENTS}

The authors wish to thank the Department of Soil Science and Agricultural Chemistry, Tamil Nadu Agricultural University, Coimbatore, for providing a laboratory facility during the study period.

\section{Conflict of interest}

The authors declare that they have no conflict of interest.

\section{REFERENCES}

1. Ahamed, S. S., Jawahar, D., Chitedshwari, T. \& Sundara, D. J. (2019). Synthesis and characterization of organic zinc chelates through FT-IR. J. Pharmacogn. Phytochem., 8(4), 1217-1222.

2. Amin, A., A.E.F. Gharib, A., El-Awadia, M. \& Rashad, E.S.M. (2011). Physiological response of onion plants to foliar application of putrescine and glutamine. Sci. Hortic., 129, 353-360.

3. Chaney, R.L. \& Bell, P.F. (1987). Complexity of iron nutrition: Lessons for plant-soil interaction research. J. Plant Nutr., 10, 963-994.

4. Datir, R.B., Laware, S. L. \& Apparao, B. J. (2010). Effect of organically chelated micronutrients on growth and productivity in Okra. Asian J. Exp. Sci., S1, 115-117.

5. El-Seginy, A.M., Naiema, M.S.M., Abd El-Messeih, W.M. \& Eliwa, G.I. (2003). Effect of foliar spray of some micronutrients and gibberellins on leaf mineral content, fruitset, yield, and fruit quality of Anna apple trees. Alex. J. Agric. Res., 48,137-143.

6. Ghasemi, S., Khoshgoftarmanesh, A. H., Hadadzadeh, H. \& Jafari, M. (2012). Synthesis of iron-amino acid chelates and evaluation of their efficacy as iron source and growth stimulator for tomato in nutrient solution culture. J. Plant Growth Regul., 31(4), 498-508.
7. Hsu, H. J. (1996). Metal amino acid chelate. United States Patent (USOO5504055A). Retrieved from https://patents. google.com/patent/US5504055A/en

8. Josemaría, G.M., Rodrigo, G., Cantera \& Angel, Z. (2003). Interaction of different iron chelates with an alkaline and calcareous soil: A complementary methodology to evaluate the performance of iron compounds in the correction of iron chlorosis, J. Plant Nutr., 26, 1943-1954.

9. Kobayashi, T., Itai, R. N., \& Nishizawa, N. K. (2014). Iron deficiency responses in rice roots. Rice, 7(1), 1-11.

10. Kumar, V., Kumar, D., Singh, Y. V., \& Raj, R. (2015). Effect of iron fertilization on dry-matter production, yield and economics of aerobic rice (Oryza sativa). Indian $\mathrm{J}$. Agron., 60(4), 547-553.

11. Manonmani, V., \& Srimathi, P. (2009). Influence of mother crop nutrition on seed yield and quality of blackgram. Madras Agric. J, 96(1-6), 125-128.

12. Mohammadipour, R., Sed.aghat Hoor, S., \& MahboubKhomami, A. (2013). Effect of application of iron fertilizers in two methods foliar and soil applications on growth characteristics of Spathiphyllum illusion. Eur. J. Exp. Biol., 3, 232-240.

13. Pal, S., Datta, S. P., Rattan, R. K. \& Singh, A. K. (2008). Diagnosis and amelioration of iron deficiency under aerobic rice. J. Plant Nutr, 31(5), 919-940.

14. Schaffer, B., Crane, J. H., Li, C., Li, Y., \& Evans, E. A. (2011). Re-Greening of lychee (Litchi chinensis Sonn.) leaves with foliar applications of iron sulfate and weak acids. J. Plant Nutr., 34(9), 1341-1359.

15. Schulte, E., \& Kelling, A. (2004). Understanding plant nutrients: Soil and applied copper. A2527. University of Wisconsin-Extension.

16. Zeid, I.M. (2009). Effect of arginine and urea on polyamines content and growth of bean under salinity stress. Acta Physiol. Plant, 31, 65-70.

17. Zimbovskaya, M. M., Polyakov, A. Y., Volkov, D. S., Kulikova, N. A., Lebedev, V. A., Pankratov, D. A. \& Perminova, I. V. (2020). Foliar application of humic-stabilized nanoferrihydrite resulted in an increase in the content of iron in wheat leaves. Agronomy, 10(12), 1891. https:// doi.org/10.3390/agronomy10121891 